For inclusion in Seminars in Diagnostic Pathology:

\title{
PROLIFERATIVE, REPARATIVE, \& REACTIVE BENIGN BONE LESIONS THAT MAY BE CONFUSED DIAGNOSTICALLY WITH TRUE OSSEOUS NEOPLASMS
}

\author{
Mark R. Wick, MD \\ Department of Pathology \\ University of Virginia Health System, Charlottesville, VA \\ (mrwick1@usa.net) \\ Michael B. McDermott, MB, MRCPath \\ Department of Pathology \\ Our Lady's Hospital for Sick Children, Crumlin, Dublin 12, Ireland \\ (Michael.mcdermott@olhsc.ie) \\ Paul E. Swanson, MD \\ Department of Pathology \\ University of Washington Medical Center, Seattle, WA \\ (ps3@uw.edu)
}


The interpretative problems associated with intraosseous or parosteal pseudoneoplasms may be either radiographic or histological ones. Even radiographically-bland lesions may contain unexpectedly-cellular fibro-osseous or chondro-osseous tissues that are difficult to separate microscopically from those seen in osteosarcoma, chondrosarcoma, chondroblastoma, or giant cell tumor.

This review considers selected osseous lesions that can be mistaken for true neoplasms, with emphasis on pathological differential diagnosis. It has been structured so as overlap minimally with the contents of a prior exposition on this topic in Seminars in Diagnostic Pathology by Hoch \& Montag (1).

\section{Fibrous \& Fibro-osseous Proliferations of Bone}

\section{Fibrous Dysplasia}

The inclusion of fibrous dysplasia in a discussion of pseudoneoplastic proliferations of bone reflects the bias of the authors. It must be acknowledged that neither fibrous dysplasia nor cortical osteofibrous dysplasia has been granted unequivocally nonneoplastic status by consensus.

Fibrous dysplasia (FD) is a fibroproliferative process in one (monostotic) or several (polyostotic) bones. It manifests a haphazardly-distributed osseous component represented by unusual configurations of woven bone (2-5). Patients with polyostotic lesions are almost always young children $(6,7)$, and many of them also have the pigmentary, endocrine, and soft tissue lesions of Albright disease $(5,6)$. Most patients with polyostotic FD exhibit symptoms before the age of 10 years. The incidence of soft tissue and intramuscular myxomas is increased in patients with FD, particularly those with polyostotic disease (8). Monostotic fibro-osseous proliferations generally affect older children or young adults, although not exclusively. The majority of FD lesions undergo enlargement during normal phases of bone growth, and they become stable in size and appearance when skeletal maturity is attained. Approximately one-third of monostotic FD is seen in the craniofacial bones, where it usually presents as a painless deforming lesion (2). Long bones-- especially the femur and tibia-- also account for about one-third of the lesional sites (4). There, FD may present with pain as a result of intra- or perilesional fracture (290). Patients with polyostotic lesions tend to have pelvic involvement, in addition to lesions in the long bones of the legs (2).

The radiographic and pathologic features of monostotic and polyostotic FD are similar. Plain-film radiographs reveal a range of ossification that is independent of lesional size. Lightly mineralized lesions also may be cystic, and they may occasionally disrupt the bony cortex with a periosteal reaction. Although a thin sclerotic rim usually separates FD from adjacent bone, some examples appear to blend with the adjacent cortex.

The gross appearance of resected FD is that of a firm fibrous mass with a variable amount of calcified matrix (Fig. 85). Serous or blood-filled cysts may develop secondarily, and, in approximately $10 \%$ of lesions, nodules of mature cartilage may be encountered (9). Extensive chondroid differentiation has engendered such names as fibrocartilaginous dysplasia (10) and 
fibrocartilaginous mesenchymoma (11); however, the relationship of those lesions to each other and to classical FD is somewhat unclear.

On histological examination, FD manifests irregularly shaped, delicate trabeculae of woven bone, in a moderately cellular fibrous stroma. Mineralized osteoid matrix is typically heterogeneous; osteoblasts are loosely admixed with matrix in amorphous areas and within immature or developing trabeculae (Figure 1). In the latter respect, FD may resemble welldifferentiated intraosseous osteosarcoma, a neoplasm whose common location in the proximal tibia may also overlap that of monostotic dysplasia (Figure 2). The absence of atypia in the osteoblastic population of FD, together with the paucity of osteoblasts within maturing trabeculae distinguishes that pseudoneoplasm from its malignant mimic. In well-developed lesions, osteoblastic "rimming" is largely absent from the trabeculae of FD. When cartilage is present, it shows continuity with ossifying elements.

The fibrous stroma of FD is itself heterogeneous, varying in cellularity and the extent of collagenization. Myxoid changes also may be conspicuous. Stromal cells generally resemble fibroblasts by both light and electron microscopic examination. Cytological atypia, if present at all, is only modest. Occasional multinucleated cells may be present, although aggregates of them are unusual (12). Such elements may occasionally evoke a resemblance to giant cell reparative granuloma, as discussed later. In areas where a collagenized stroma predominates, FD may resemble metaphyseal fibrous defect or desmoplastic fibroma. In the first of these lesions, cellularity is greater, with more osteoclast-like giant cells and histiocytes. On the other hand, desmoplastic fibroma shows a well-organized, paucicellular collagenous matrix (13) (Figure 3). When FD affects the tibia, a challenging differential diagnosis is that of cortical osteofibrous dysplasia, as reviewed below.

Although the risk for malignant transformation of FD (most commonly in the form of osteosarcoma, and, less often, as malignant fibrous histiocytoma, fibrosarcoma, or chondrosarcoma) is very low, that phenomenon is unpredictable (14-16). An antecedent history of radiation therapy for FD — which is ill-advised - pertains to the majority of cases with malignant transformation, but as many as one-third of sarcomas in FD arise spontaneously (14).

As mentioned above, the form of sporadic bone sarcoma which is particularly likely to be confused with fibrous dysplasia is low-grade central osteosarcoma (LGCO) (17). Commonly, it is recognized as such only after recurrence of a lesion that has previously been interpreted as FD histologically. Accurate diagnosis is predicated on correlation with results of clinical imaging studies and detailed evaluation of histologic findings. Radiographic features of LGCO are not always diagnostic, but they typically suggest a lesion with greater aggressive potential than that of fibrous dysplasia or other benign proliferations. Such attributes include indistinct circumscription, dense sclerosis, an interrupted periosteal reaction, or cortical infraction by the tumor (18). Microscopic sections through the center of LGCOs usually demonstrate woven microtrabeculae of bone in a moderately cellular, fibrous stroma (Figure 2). If sections include the interface of the lesion with normal bone, fibrous tissue within Haversian canals or between mature cancellous trabeculae is a strong sign of malignancy (17). In the absence of those findings, atypical mitotic activity may lead to the correct diagnosis. Although patients with 
LGCO usually are treated with surgery alone, and their prognosis is significantly better than with conventional osteosarcoma, a certain number of patients develop secondary high-grade osteosarcoma (by "dedifferentiation") in the original low-grade tumor, particularly in local recurrences (18). Dujardin et al. (19) have shown that immunoreactivity for murine double minute type 2 (MDM2) gene product or cyclin-dependent kinase 4 (CDK4) protein, or both, is typical of LGCO. FD and other benign fibroosseous lesions do not express those two markers.

FD has also been mistaken for other benign and malignant bone lesions. They include well-differentiated fibrosarcoma, "solid" aneurysmal bone cyst (SABC), osteoid osteoma, and osteoblastoma (2) (Figure 4). The first two of those entities lack the "nonsensically"-shaped osteoid trabeculae of FD, and they show a greater degree of cellularity. In addition, SABC contains easily-seen osteoclast-like giant cells. Osteoblastoma and osteoid osteoma demonstrate broadly-interlocking masses of osteoid which are morphologically-dissimilar to those of FD (2).

\section{Benign Fibro-Osseous Lesions of the Jaws}

One group of benign ossifying lesions is peculiar to the jawbones, exclusive of FD, which may also affect that location (21). The other proliferations are usually designated generically as "benign fibro-osseous lesions" (BFOLs), but are sometimes subdivided into two collections based on their histological characteristics. Those are "ossifying fibroma" (OF) and "cementoossifying fibroma" (COF) (22-27). The principal difference between the latter lesions is the nature of the bony matrix in them; OF produces osteoid-like material and bony trabeculae (Figure 5), whereas COF contains matrical material which strongly resembles the cementum of teeth. In some instances, it is arranged concentrically around focal points, yielding psammoma body-like structures ("psammomatous COF”) (Figure 6).

All of these lesions may expand the affected bone significantly, but they typically do not breach its cortex. Moreover, they are cytologically-bland, without pathologic mitotic figures. Thus, the conjoint radiographic and histologic features of BFOLs are unlike those of gnathic osteosarcomas (28) (Figure 7). Moreover, the latter neoplasms are characteristically chondroblastic, whereas cartilaginous tissue is distinctly unusual in BFOLs. Osteoblastomas and osteoid osteomas again differ substantially from BFOLs on imaging studies (2).

\section{Cortical Osteofibrous Dysplasia, With \& Without Adamantinoma}

In contrast to FD, the lesion known as cortical osteofibrous dysplasia (COD; Campanacci's disease) is an intracortical or subperiosteal fibro-osseous proliferation that almost exclusively affects the tibia and fibula (29-33). It is usually solitary and is not associated with Albright's disease (30). As in polyostotic FD, children in the first decade of life are typically affected by COD $(30,33)$ and presentation in early adulthood is unusual $(33)$. Although it is a deforming lesion of bone, COD is usually asymptomatic $(30,33)$. It is not associated with myxomas of soft tissue or muscle. If malignant transformation of COD occurs, it does so by evolution to the development of adamantinoma of long bones. 
The radiographic appearance of COD is that of a heterogeneously lucent intracortical mass in the diaphysis of the tibia or fibula (Figure 8). Lesional expansion appears to preserve the medullary space at the expense of subperiosteal bone (31). The cortex is occasionally effaced, but the overlying periosteum is preserved. The result is an eccentrically placed mass that produces a bowing deformity in the long axis of the bone. In adults, mature sclerotic lesions of COD may resemble Paget disease (30). As true of FD, a sclerotic rim may be seen at cortical interfaces, and it generally defines the extent of lesional growth (31).

The gross appearance of COD depends largely on the degree of ossification it shows (32). Poorly mineralized lesions comprise soft fibrous tissue, whereas others with extensive ossification may be gritty on cut section. The histologic features of COD superficially resemble those of FD, with irregular trabeculae of variably mineralized bone. An admixture of osteoblasts and osteoid matrix is usually absent. Most bone formation occurs by osteoblasts that are aligned along the peripheral surfaces of trabeculaer in COD. The supporting connective tissue is densely collagenized, with relatively few fibroblasts, although more cellular areas may be apparent in some cases. Hyaline cartilage is uncommon in COD, and when it is present, it generally is an element of a callus in a pathologic fracture. Isolated keratin-reactivity is present in the stromal cells of 33-93\% of COD cases, a finding that is not seen in FD (34-36).

The microscopic appearance of COD is dichotomous - the lesions either resemble FD (with the same differential diagnostic considerations) or they have a composite histologic image of COD with adamantinoma. The latter relationship requires further elaboration.

Adamantinoma (ADA) is a primary low-grade malignant intraosseous neoplasm that typically affects the tibial diaphysis along its anterior surface (35,37-42). Most ADAs are intracortical, although medullocentric proliferations have also been described. They are usually confined by the periosteum, and those lesions with extraosseous extension are more prone to local recurrence and metastasis. Young adults are usually affected (37-42). The singular feature of ADA is its epithelial lineage. The histologic appearance of this tumor encompasses collections of spindle cells; aggregates of basaloid cells; and glandular or tubular structures. The first of those patterns may simulate a fibroblastic or fibrohistiocytic proliferation (38.39). Irrespective of their cytological appearances, ADAs are immunoreactive for pankeratin and may also express epithelial membrane antigen or carcinoembryonic antigen $(34,35,40,43)$. In some instances, osteofibrous elements similar to those of COD are clearly admixed with the neoplastic cells of ADA (30,35,36,39,44,45) (Figure 9).

Indeed, it is now generally accepted that the form of COD containing keratin-reactive stromal cells is a precursor to ADA $(33,46)$. Therefore, biopsies showing the first of those entities should be reflexively studied immunohistologically for the expression of epithelial determinants. Kashima et al. (47) have shown that podoplanin-immunoreactivity is common to both COD and ADA, further solidifying the interrelationship between those conditions. 


\section{Metaphyseal Fibrous Defect (Nonossifying Fibroma)}

Nonossifying fibroma is, in our opinion, synonymous with the lesion known as metaphyseal fibrous defect (MFD). As such, it arises in the metaphysis of long bones, particularly the distal femur and the proximal or distal tibia (48-51); involvement of the diaphysis is unusual. Bilateral and multifocal lesions are seen in nearly one-half of patients (48). A small subset of them has neurofibromatosis (52), with cutaneous cafe-au-lait spots and other congenital abnormalities (53).

Many patients with MFDs are children, and most are less than 10 years old. MFD is a typically small intracortical lucency that is asymptomatic and often encountered incidentally. Caffey suggested that as many as one-third of prepubescent children have radiologic evidence of one or more MFDs (48). Many small lesions of this type spontaneously regress, and larger ones tend to be seen in older children or young adults as lytic defects that may cause medullary expansion (51). MFD may present with pain that is related to pathologic fracture (54). That lesion arises at or near sites of tendinous insertions, and it may focally erode the outer cortex. The location and the pattern of metaphyseal damage in MFD support musculoskeletal injury as an important etiologic factor $(50,51)$.

The radiographic appearance of MFDs is characteristic, and it allows for accurate diagnosis in most cases. Lytic zones in the lesion are sharply demarcated from adjacent cortical bone by a thin sclerotic rim (Figure 10). The conjoint clinical and radiological attributes of MFD generally permit confident nonsurgical management of small lesions, as well as conservative surgery for larger and potentially unstable lytic lesions $(51,52)$.

It must therefore be acknowledged that most MFDs do not present a great diagnostic challenge for the radiologist or pathologist. However, in cases that present in young adults, the radiographic appearance may be indeterminate. MFD may undergo progressive mineralization and remodeling, resulting in an irregular configuration and density of the lesion (51). After pathologic fracture, medullary hemorrhage, periosteal reaction, or early callus formation in MFD may further mask its characteristic features. Foam cells and hemosiderin deposites are potentially conspicuous in older lesions. Ossification is not a usual element of MFDs; rather, bony trabeculae in them are either reactive in nature or they represent residual cortical elements at the periphery of the lesions $(50,55)$. These trabeculae have an "orderly" structure, permitting their distinction from those seen in FD or COD. The stroma of MFD may contain variable amounts of collagen, but dense hyalinization is distinctly uncommon. If it is present, a resemblance to desmoplastic fibroma may obtain, but the storiform configuration spindle cells in MFD effectively excludes that diagnostic alternative. Malignant transformation of MFD probably does not occur, although Kyriakos and Murphy (56) reported an apparently coincidental MFD juxtaposed to an osteosarcoma.

With regard to differential diagnosis, it is probably not possible to separate fibrous histiocytoma (FH) of bone from MFD on histologic grounds alone (56-58). Nevertheless, FHs do not show an exclusive localization in the metaphysis of long bones, as does MFD. Involvement of bones by FHs is often diaphyseal, with potential extension to the metaphysis or 
epiphysis; moreover, they most often affect axial skeletal sites, unlike MFDs. FH of bone also continues to be seen throughout adulthood, and, in further contrast to MFD, it may be painful even in the absence of fracture. Finally, osseous FH may recur after curettage or it may sometimes behave in a locally aggressive fashion (57). In general, the differential diagnosis between MFD and FH is only problematic in metaphyseal lesions in long bones in patients over the age of 25 years. Arbitrary bias on the diagnostic side of FH may be appropriate in those cases, to assure proper surgical management.

\section{Fibroinflammatory \& Reactive-Reparative Lesions}

\section{Giant Cell Reparative Granuloma}

Giant cell reparative granuloma (GCRG) is a clinically-distinctive intraosseous proliferation that contains numerous osteoclast-like giant cells. It is most often encountered in the mandible or, less commonly, the maxilla (60-63) (Figure 11). Cranial bones are only rarely affected $(63,64)$. Multiple lesions in the mandible, particularly if they are symmetric and bilateral, may present the image of the heritable disease known as "cherubism" (65). Apart from exceptional cases of true giant cell tumors, some of which are associated with Paget disease of bone (66-68), few other lesions enter the differential diagnosis of GCRG. However, it has also been described in distal appendicular skeletal sites, most notably the phalanges or metatarsal and metacarpal bones (69-74) (Figure 12). Most GCRGs are solitary, and multifocal examples tend to be those in the distal extremities (68).

Although GCRGs in the hands and feet are seen over a wide age range, most patients are in the second to fourth decades of life, and most of them are over the age of 30 years at diagnosis (73). Those figures overlap with the peak incidence of true giant cell tumor (GCT), although, on average, patients with that true neoplasm are older (2). The symptoms of swelling and pain are variable in cases of GCRG, and prior trauma does not appear to be a common element in the clinical presentation $(70,74)$.

The radiographic appearance of GCRG is that of an expansile but well-delimited lytic lesion beneath an attenuated but intact cortex. Although most of the lesions are radiolucent, internal trabeculae of mineralized tissue are sometimes evident. Involvement of periosteal or extraosseous soft tissue by GCRG is distinctly uncommon $(64,72)$. There is no perilesional sclerosis, and periosteal reactions are generally absent $(70,73)$. With the exception of rare epiphyseal GCRGs described by Lorenzo and Dorfman (71), distal lesions of this type are almost exclusively centered in the metaphysis or diaphysis of the affected bone. This localization provides a useful point of contrast with typical examples of GCT, which is an epiphyseal tumor (2).

Macroscopically, GCRG has no singular characteristics. Heterogeneously-colored soft tissue predominates $(69,71)$, but areas of cystic degeneration may also be present $(73)$.

Histologically, the lesion contains irregularly-distributed multinucleated osteoclast-like giant cells in a supporting fibrous stroma that varies in cellularity. The background cell population comprises fusiform or ovoid fibroblasts, and paucicellular hyalinized areas may be appreciated 
as well (Figures $11 \& \mathbf{~ 1 2 )}$ ). Reactive bony trabeculae and islands of osteoid are interspersed in the fibroblastic and giant cell proliferation, but most mature osseous elements are encountered at the lesional periphery. In areas where they are inconspicuous, the lesion may resemble MFD histologically $(71,73)$. Most bony trabeculae in giant cell reparative granuloma are mantled with osteoblasts, but if they are lacking, an image results which can simulate that of FD (71). The giant cells in GCRG are principally centered on areas of hemorrhage or clustered in aggregates (Fig. 113). Cystic vascular spaces also may arise secondarily in this lesion, producing an appearance like that of aneurysmal bone cyst (ABC). Indeed, it is likely that GCRG and ABC belong to the same broad family of reparative-reactive bone lesions.

There are no particular immunohistochemical or electron microscopic features that allow for a unique characterization of GCRG. Moreover, its biochemical and ultrastructural phenotype overlaps in large part with that of GCT (75).

As implied in the foregoing discussion, the most important differential diagnosis for GCRG is that of GCT. The lack of epiphyseal involvement by GCRG is a helpful feature. Furthermore, the fibroblastic nature of background elements and the irregular distribution of giant cells in that lesion separates it from the typical microscopic image in GCT. That tumor has a more uniformly ovoid stromal-cell population, the nuclei in which share a morphological likeness to those of the giant cells (2) (Figure 13). In GCRG, the stromal-cell nuclei are elongated with tapered ends (2). The accurate diagnosis of GCT has considerable importance because of its tendency for recurrence, and its rare ability to undergo sarcomatous transformation or metastasize.

\section{Brown Tumor of Hyperparathyroidism}

The giant cell lesion of hyperparathyroidism (GCLH; "brown tumor") is basically indistinguishable from giant cell reparative granuloma histologically, but the former of those lesions invariably arises in patients with clinical or laboratory evidence of hyperparathyroidism. That condition is reflected by increased serum levels of calcium, phosphate, alkaline phosphatase, and parathyroid hormone (76-78). The absence of such laboratory changes is an obligate criterion for the diagnosis of GCRG. The one point of morphological difference between GCLH and GCRG is that brown tumors are also associated with microscopic evidence of active bone resorption, with numerous osteoclasts mantling bone trabeculae (Figure 14). Nevertheless, that observation requires a sampling of adjacent non-lesional bone.

Brown tumors are also accompanied by radiographic evidence of diffuse osteopenia in plain-film radiographs of the hands and feet, often with erosion of the tufts of the phalanges. The calvarium is similarly affected, producing a "salt and pepper" skull $(76,77)$. Favored anatomic locations for the tumefactive lesions include the vertebral bodies, distal clavicle, symphysis pubis, and lamina dura of the jawbones (77). In rare instances, several bones harbor brown tumors simultaneously, and they may thus imitate the radiographic appearance of osseous metastases $(77,78)$. 
The metaphyseal location of aneurysmal bone cyst (ABC), and the tendency for giant cells to aggregate near cystic or hemorrhagic foci, make the histologic appearance of that lesion difficult to distinguish from giant cell reparative granulomas and brown tumors as well, particularly when solid foci predominate (79-81). The potential presence of secondary cystic change in GCRG and GCLH further complicates this differential diagnosis. Convention dictates that the presence of lesions resembling $\mathrm{ABC}$ in the bones of hands and feet should be interpreted as representing GCRG or GCLH in those locations (75).

\section{Synovial Chondrometaplasia-Synovial Chondromatosis}

As a primary metaplasia, synovial chondromatosis (SC) is distinctive among pseudoneoplasms in skeletal and articular tissues. Usually monoarticular in nature, synovial chondromatosis arises as a multinodular process in synovium, bursa, or tendon sheaths in or around the large joints, particularly the knee. The nodules secondarily detach themselves, becoming free in the synovial spaces as loose bodies (82-88). Extraarticular lesions can also occur (89).

The radiographic appearance of SC in both intra- and extraarticular sites is variable, although most lesions are characteristically radiolucent. Varying degrees of mineralization reflect a tendency for the cartilaginous nodules to calcify or undergo ossification (82-84).

Histologically, SC is represented principally by mature hyaline cartilage. However, constituent nuclei may be hyperchromatic with large irregular shapes, and multinucleated chondrocytes might be present (Figure 15). Cellular areas may also exhibit varying degrees of mitotic activity, but the overall architectural and cytological atypia that typifies chondrosarcoma is absent. Separation of SC from enchondroma is not problematic because of the clearlyintraosseous location of the latter tumor, but a distinction of metaplastic cartilage from soft part chondromas might not be possible in the circumstance when chondromatosis occurs in or near synovial tissues. This situation is further complicated by an increased incidence of true cartilaginous neoplasms of the soft tissue in patients with SC $(90,91)$. Nevertheless, the benign clinical behavior of soft tissue chondromas makes this distinction unimportant pragmatically.

The pattern of ossification in SC resembles normal enchondral ossification; osteoblastic atypia is not seen. The nodular growth of SC, detached from bone, likewise precludes the misdiagnosis of osteochondroma (92). Although malignant transformation to chondrosarcoma has occurred in rare, anecdotal instances of SC (93-96), local persistence of chondrometaplasia is a more common problem (86). Typical chondrosarcoma is an intraosseous process (Figure 16), differing from the clinicopathologic profile of SC.

\section{Aneurysmal Bone Cyst}

Aneurysmal bone cysts (ABCs) are generally encountered in the metaphysis of long bones or in vertebrae, although virtually any other bone in the body may occasionally harbor them $(80,81)$. Most aneurysmal bone cysts affect young individuals, usually before the third decade of life. 
The lesions are often painful, and they may be symptomatic for only relatively short periods of time before clinical diagnosis $(80,81,97-100)$.

In long bones, $\mathrm{ABCs}$ most often arise in the distal femur and proximal tibia $(80,97,98,100)$. In vertebrae, they often affect the posterior arch and spinous processes-- with secondary extension into the vertebral body-- and have a peculiar tendency to involve adjacent bones (100). Lesions in small bones of the distal extremities have also been described (101). The majority arises in cortical or medullary bone; fewer than $10 \%$ primarily are seen in subperiosteal sites $(102,103)$.

The radiographic appearance of $\mathrm{ABC}$ evolves over the life of the lesion (102-104). Initially, it is small, often eccentrically-placed in the affected bone, and does not expand the cortex. In this "incipient" phase, the borders of the lesion are indistinct and may exhibit a permeative pattern of growth into adjacent cortex or medulla. In the so-called "growth" phase of ABC, rapid enlargement is associated with bony expansion, osteolysis, and cortical destruction. There may be sufficient periosteal injury to cause formation of a "Codman's triangle" radiographically, as seen in osteosarcoma. In rapidly-enlarging lesions, portions of the cortex may appear to be lost entirely. However, the medullary margins of the lesion remain distinct, a feature that may help to distinguish proliferative $\mathrm{ABC}$ from osteosarcoma or other intraosseous malignancies. Following rapid expansion, $\mathrm{ABC}$ assumes a more stable phase wherein the classic radiographic appearance emerges of an expanded, lytic, trabeculated, metaphyseal lesion with distinct perilesional sclerosis. With time, the trabeculae may progressively ossify (100).

The gross appearance of intact $\mathrm{ABC}$ is not often seen in surgical specimens, because only curetted fragments are submitted to the pathology laboratory. In larger pieces of tissue, or when the entire lesion is available for examination, the most conspicuous feature is a catacomb of cavernous or aneurysmal blood-filled spaces $(80,99)$. The prominence and thickness of more solid trabeculae within the lesion depends on the stage of incisional growth in which the specimen has been obtained. In older lesions, coarse bony trabeculae may be prominent. The lesion, apart from its aneurysmal characteristics, may also be conspicuously cystic with serous and serosanguinous fluid filling irregularly sized spaces. Predominantly or exclusively solid variants of $\mathrm{ABC}$ are uncommon $(105,106)$.

The histologic features of aneurysmal bone cyst are variable from case to case, but they encompass a fairly consistent range of features that allow for confident diagnosis in the majority of cases $(80,81,97-99)$. Cystic or aneurysmal blood-filled spaces, from which the name of the lesion is derived, are characteristic of all but the solid variant lesions (Figure 17). Neither careful histologic, ultrastructural, nor immunohistochemical analyses have identified an endothelial lining on the surface of these spaces $(100,107,108)$, although the presence of arteriovenous malformations within resected aneurysmal bone cysts suggests that vascular trauma may be an important factor in their development $(97,109)$. The aneurysmal spaces are separated by fibrous septa of varying thicknesses and configurations that are relatively cellular, populated by fibroblasts and an admixture of chondroid or osteoid matrix, multinucleated giant cells, mononuclear histiocytoid cells, and a bland lymphoplasmocytic inflammatory infiltrate. Giant cells may congregate beneath the lining of the blood-filled spaces but do not actually 
constitute an element of the lining or reside within the space. In many areas, the admixture of cellular elements may resemble those seen in giant cell reparative granuloma or giant cell tumor.

Ossification within the lesion may be conspicuous in older lesions. Bone formation either arises as a mineralization of osteoid in a manner very similar to that seen in fibrous dysplasia or develops together with a rim of primitive chondromyxoid matrix $(20,100)$. The latter, regarded by some as characteristic of ABC (81), often occupies large areas in the septa that are independent of osteoid and may line the blood-filled spaces. This characteristic matrix often calcifies in a focal, heterogeneous pattern that clearly distinguishes $\mathrm{ABC}$ from chondroblastoma (2). Osteoid is often conspicuous in calcifying $\mathrm{ABCs}$, and may assume a linear, trabeculaer, or lace-like configuration. The matrix is usually associated with mitotically active but cytologically bland mononuclear cells. At the periphery of the lesion, aneurysmal spaces may interdigitate with cortical bone; in lesions that have eroded through the cortex, the characteristic histologic components of $\mathrm{ABC}$ may also be present in extraperiosteal soft tissue (100).

In cases of "solid" ABC $(105,106)$, all of the features evident in the septa of typical examples are represented, including the distinctive chondroid matrix. But for lack of aneurysmal spaces, the juxtaposition of these elements bears a strong resemblance to the image of GCRG. Because most of the solid lesions reported by Sanerkin \& colleagues (110) also contained small foci in which ectatic blood-filled spaces were present, the diagnosis of aneurysmal bone cyst may have been justified in that series of cases. However, it is accepted that many lesions histologically characteristic of $\mathrm{ABC}$ are associated with, or arise as a secondary phenomenon in, several intraosseous lesions (104,110-112). These include GCRG and GCT, among others. Although the anatomical distributions of $\mathrm{ABC}$ and GCRG do not overlap to any great extent, the microscopic similarities between those lesions suggest a common histogenesis (106). This relationship also serves to emphasize the fact that the diagnosis of primary $\mathrm{ABC}$ requires that another definable lesion of bone must be excluded first. The morphological elements of $\mathrm{ABC}$ may be superficially recapitulated in selected osteosarcomas, osteoblastomas, GCTs, chondroblastomas, and chondromyxoid fibromas. So common is the association between aneurysmal changes and GCRG-like foci that some authors have suggested that all ABCs are secondary phenomena, wherein the original lesion is "overrun" and no longer identifiable (112). However, we do not subscribe to that view.

Apart from the separation of "solid" ABC from GCRG in appendicular sites, and the exclusion of other primary underlying lesions, the differential diagnosis of $\mathrm{ABC}$ is based on the nature and distribution of its osseous elements. Even though $\mathrm{ABC}$ may be somewhat destructive in some cases, and it may contain mineralizing osteoid and mitotically-active cells, the clinicopathologic confusion between ABC and telangiectatic osteosarcoma (TOS) (113-117) should be an uncommon event. Nevertheless, that is the most serious diagnostic problem encountered in this context. In TOS, compact irregular trabeculae of osteoid are associated-with cytologicallyanaplastic osteoblasts that contain atypical mitotic figures (115) (Figure 18). In addition, that tumor is virtually always overtly aggressive, with marked expansion of the affected bone, destruction of its cortex, and common extraosseous extension into adjacent soft tissue (114). 
Although large, destructive $\mathrm{ABCs}$ require surgical resection, curettage or excision with bone grafting is the usual therapy for this lesion $(100,101)$. Recurrence of true $\mathrm{ABC}$ may be see within 6-24 months if subtotal removal is effected $(100,102,109)$, and ABC-like changes may also be seen in recrudescent true neoplasms, as mentioned above (97). Malignant transformation in primary $\mathrm{ABC}$ is extraordinarily rare, and is usually associated with a prior history of radiation therapy (100). Kyriakos \& Hardy also have reported one case in which no such previous treatment was given (118).

\section{Tumefactive Chronic Osteomyelitis}

In both its acute and chronic forms, osteomyelitis (OM) typically presents few clinical diagnostic problems. Patients with that condition characteristically have had a known bacterial infection previously - either a localized or a systemic one-and they are febrile with malaise, leukocytosis, and discomfort in the affected bone or bones $(119,120)$.

Nonetheless, occasional examples of chronic OM lack those features altogether, and present themselves with vague pain at a single infected site. Radiographic findings in such circumstances may be represented by a relatively well-demarcated, lucent, or mixed-density tumefactive lesion in the diaphysis or metaphysis (121-127). Alternatively, diffuse expansion of the bone may be observed, sometimes with periosteal changes that resemble those of "Codman's triangle." In the first of those settings, osteoid osteoma may be suspected diagnostically (128)

(Figures 19 \& 20); in the second, Ewing sarcoma or lymphoma is commonly considered interpretatively (121-127,129-133) (Figures 21 \& 22).

Yet another variant of chronic OM has a similar name, but it is noninfectious in nature and does not respond to antibiotics. That condition is called $\underline{\mathbf{c}}$ hronic recurrent $\underline{\mathbf{m}} \mathbf{u}$ tifocal $\underline{\mathbf{o}}$ steomyelitis (CRMO), which has a preference for female patients in late childhood and adolescence (134136). The onset of CRMO is typified by malaise and bone pain at the lesional sites. Early on, that disorder may be unifocal, but it characteristically progresses to yield multifocal metaphyseal lesions. Differential diagnosis thus may include a metastatic solid tumor, a hematolymphoid malignancy, and Langerhans-cell histiocytosis. Some affected individuals also have cutaneous palmoplantar pustulosis. Once the clinicopathologic diagnosis of CRMO is established, treatment with nonsteroidal anti-inflammatory agents is recommended, rather than the use of antibiotics.

Regardless of whether the patient in question has postinfectious chronic OM or CRMO, histologic findings in biopsies or curettage specimens are comparable $(121,122,136)$. They include an infiltrate of lymphocytes, plasma cells, and histiocytes in the bony medulla, with inflammatory involvement of osseous trabeculae and the presence of devitalized bone.

Secondary cortical osteogenesis may be evident as well, but a "nidus" is not seen as in cases of osteoid osteoma. Histochemical stains for microorganisms are virtually always negative in cases of chronic OM.

If the latter diagnosis is being considered microscopically, the size and nature of the surgical sample must be considered. Curettage specimens comprising a good volume of tissue are the 
most reliable pathologic substrates. On the other hand, changes resembling those of chronic OM may be seen adjacent to other bony lesions-including neoplasms - and, therefore, needle biopsy specimens may be non-representative and are not as dispositive.

The radiological and microscopic features of diagnostic alternatives such as Ewing sarcoma and lymphoma are discussed elsewhere in this issue of Seminars. In selected circumstances, either of those tumors could be confused with chronic OM radiographically and histologically.

A well-recognized complication of chronic $\mathrm{OM}$ is the formation of draining osteocutaneous fistulas. Rarely, those lesions may, over time, give rise to secondary squamous cell carcinomas of the skin, which may grow downward into the underlying bone (137).

\section{Proliferative \& Tumefactive Paget Disease of Bone}

Paget disease of bone (PDB), also known as osteodystrophia deformans, is a metabolic condition that may have an etiological association with prior viral infections $(138,139)$. It typically progresses sequentially through three phases of development, featuring osteoclastic activity; mixed osteoclasis \& osteoblastosis; and osteoblastic proliferation. A single focus of disease may be present, but it is more typical to see polyostotic PDB. The skull, vertebrae, and long bones are primarily affected, and pain at the lesional sites is common. Various biochemical abnormalities are also present in PDB, including elevation of the serum level of alkaline phosphatase in the face of normocalcemia, and elevated urinary levels of pyridinoline and hydroxyproline. The latter moieties are indicators of increased bony turnover (139).

Histologically, one initially observes an increase in bone resorption in PDB, associated with the presence of numerous large osteoclasts. This osteolytic phase is followed by compensatory bone formation with induction of osteoblastic activity and accelerated deposition of lamellar trabecular bone with a disorganized pattern $(76,138,139)$. It is often called "mosaic," in contrast to the normal linear lamellar image. Marrow spaces are replaced by fibrous tissue and a proliferation of blood vessels, causing the bone to become hypervascular. At the end-stage of PDB, only densely sclerotic and mosaic lamellar bone is apparent, and gross deformations are characteristic (138).

In approximately $1 \%$ of cases, a primary osseous malignancy makes its appearance in PDB (139) (Figure 23). Osteosarcoma is most often seen, but high-grade fibrosarcoma or pleomorphic sarcoma is evident in approximately $10 \%$ of transformed cases $(67,140-142)$. Sarcomatous evolution in Paget disease is typified by increased pain in the affected bone, and an overtlydestructive lesion that is superimposed on the usual image of PDB in plain film radiographs (141).

Rarely, the proliferative phase of Paget disease may itself produce a mass, the clinical and radiological appearances of which are strongly suggestive of a sarcoma. When such lesions are subjected to biopsy or excision, they show only the typical image of PDB histologically, with no evidence of malignancy (143-146) (Figure 24). Nevertheless, a report by Franchi et al. (147) complicates this situation. Those authors documented 2 cases in which low-grade osteosarcomas 
produced trabecular bone with a pagetic image, imitating the pattern of osteogenesis in PDB. If interpretative doubt exists, one may utilize immunostains for MDM2 gene product-as discussed earlier-in this context. PDB is MDM2-negative, whereas osteosarcomas typically express that marker (19). Pseudotumor formation in Paget disease does not alter the prognosis of that condition, but it may require additional surgical intervention to alleviate pain or correct a gross deformity.

\section{Polyvinylpyrrolidone Storage Disease}

Polyvinylpyrrolidone (PVP) is a polymer that has been used in the past as a plasma expander in transfusion medicine; it also has been employed as a food additive, a carrier for certain injectable medications, and a constituent of some hair-care products (148). When PVP enters the circulation, it cannot be excreted in the urine and is potentially deposited in several tissue sites. These include the bones, skin, liver, spleen, and lymph nodes (149). In the first of those locations, PVP storage disease may produce single or multiple lytic osseous defects that simulate the appearance of a primary or metatatic neoplasm radiographically.

Microscopically, one sees sheets of large epithelioid cells with vacuolated, sometimes-bluish cytoplasm in this condition. Their nuclei are often eccentric, and they are bland morphologically (Figure 25) (150-153). The histological differential diagnosis for PVP storage disease in bone can include such tumors as benign intraosseous notochordal neoplasms, chordoma, and metastatic signet-ring-cell adenocarcinoma, and endogenous storage disorders such as the mucopolysaccharidoses and mucolipidoses $(149,151,154)$.

The histochemical profile of PVP storage disease is characteristic. It includes reactivity with Best's' mucicarmine method, as well as the colloidal iron, methenamine silver, Congo red, Fontana-Masson, phosphotungstic acid-hematoxylin, and Victoria-blue stains. On the other hand, the periodic acid-Schiff, alcian-blue, and Giemsa techniques yield negative results $(149,152)$. That constellation of findings distinguishes PVP storage disease from its morphological imitators. Moreover, unlike chordoma, other notochordal tumors, and carcinomas, this condition fails to label for pankeratin by immunohistochemistry (148). The chemical identity of PVP can be established by mass spectroscopy done on excised tissue from the lesions (155).

Depending on the quantity of PVP that has been infused or otherwise absorbed parenterally, the number of resulting lesions is greatly variable in affected organ sites. They may be only asymptomatic radiographic findings in bone, or, alternatively, they may produce lytic lesions that can be the foci for pathologic fractures (148). 


\section{REFERENCES}

1. Hoch B, Montag A: Reactive bone lesions mimicking neoplasms. Semin Diagn Pathol 2011; 28: 102-112.

2. Unni KK, Inwards CY: Dahlin's Bone Tumors ( $6^{\text {th }}$ Ed.). Lippincott-Williams \& Wilkins, Philadelphia, 2010.

3. Fechner RE. Problematic lesions of the craniofacial bones. Am J Surg Pathol 1989; 13(Suppl 1): 17-31.

4. Lichtenstein L, Jaffe HL. Fibrous dysplasia: a condition affecting one, several or many bones, the graver case of which may present with abnormal pigmentation of skin, premature sexual development, hyperthyroidism or still other extraskeletal abnormalities. Arch Pathol 1942;33:777-816.

5. Reed RJ. Fibrous dysplasia of bone. A review of 25 cases. Arch Pathol 1963;75:480-495.

6. Albright F, Butler AM, Hampton AO, Smith P. Syndrome characterized by osteitis fibrosa disseminata, areas of pigmentation and endocrine dysfunction with precocious puberty in females. N Engl J Med 1937; 216: 727-746.

7. Pelzmann KS, Nagel DZ, Salyer WR. Case report 114 (polyostotic fibrous dysplasia and fibrochondrodysplasia). Skeletal Radiol 1980;5:116-118.

8. Wirth WA, Leavitt D, Enzinger FM. Multiple intramuscular myxomas: another extraskeletal manifestation of fibrous dysplasia. Cancer 1971;27:1167-1173.

9. Harris WH, Dudley HR Jr, Barry RJ. The natural history of fibrous dysplasia. J Bone Joint Surg (Am) 1962;44:207_ 233.

10. Ishida T, Dorfman HD. Massive chondroid differentiation in fibrous dysplasia of bone (fibrocartilaginous dysplasia). Am J Surg Pathol 1993;17:924-930.

11. Bulychova IV, Unni KK, Bertoni F. Beabout JW. Fibrocartilagenous mesenchymoma of bone. Am J Surg Pathol 1993;17:830-836.

12. Henry A: Monostotic fibrous dysplasia. J Bone Joint Surg (Br) 1969; 51: 300-306.

13. Böhm P, Kröber S, Greschniok A, Laniado M, Kaiserling E. Desmoplastic fibroma of the bone. A report of two patients, review of the literature, and therapeutic implications. Cancer 1996; 78: 1011-1023.

14. Huvos AG, Higginbotham ML, Miller TR. Bone sarcomas arising in fibrous dysplasia. J Bone Joint Surg (Am) 1972;54:1047-1056.

15. Ishida T, Machinami R, Kojima T, Kikuchi F. Malignant fibrous histiocytoma and osteosarcoma in association with fibrous dysplasia of bone. Report of three cases. Pathol Res Pract 1992;188:757-763.

16. Ruggieri P, Sim FH, Bond JR, Unni KK. Malignancies in fibrous dysplasia. Cancer 1994;73:1411-1424.

17. Unni KK, Dahlin DC, McLeod RA, Pritchard DJ: Intraosseous well-differentiated osteosarcoma. Cancer 1977; 40: $1337-1347$.

18. Hayashi K, Tsuchiya H, Yamamoto N, et al.: Diagnostic and treatment of low-grade osteosarcoma: experience with nine cases. Int J Clin Oncol 2013 (E-publication, 7-24-13) (Accessed 10-11-13).

19. Dujardin F, Nguyen MB, Bouvier C, et al.: MDM2 and CDK4 immunoreactivity is a valuable tool in the differential diagnosis of low-grade osteosarcoma and other primary fibro-osseous lesions of the bone. Mod Pathol 2011; 24: 624-637. 20. Capanna R, Campanacci DA, Manfrini M: Unicameral and aneurysmal bone cysts. Orthop Clin N Am 1996; 27: 605614.

21. Slootweg PJ: Maxillofacial fibro-osseous lesions: classification and differential diagnosis. Semin Diagn Pathol 1996; 13: $104-112$

22. Alsharif MJ, Sun ZJ, Chen XM, Wang SP, Zhao YF: Benign fibro-osseous lesions of the jaws: a study of 127 Chinese patients and review of the literature. Int J Surg Pathol 2009; 17: 122-134.

23. Mithra R, Baskaran P, Sathyakumar M: Imaging in the diagnosis of cemento-ossifying fibroma: a case series. J Clin Imaging Sci 2012; 2: 52 (E-publication 8-30-12) (Accessed 10-11-13).

24. Patigaroo SA, Juvenile psammomatoid ossifying fibroma of maxilla: a rare entity. J Maxillofac Oral Surg 2011; 10: 155-158.

25. More C, Thakkar K, Asrani M: Cemento-ossifying fibroma. Indian J Dent Res 2011; 22: 352-355.

26. Yoon JH, Kim J, Lee CK, Choi IJ: Clinical and histopathological study of fibro-osseous lesions of the jaws. Yonsei Med J 1989; 30: 133-143.

27. Hamner JE III, Scofield HH, Cornyn J: Benign fibro-osseous jaw lesions of periodontal membrane origin: an analysis of 249 cases. Cancer 1968; 22: 861-878.

28. Paparella ML, Olvi LG, Brandizzi D, Keszler A, Santini-Araujo E, Cabrini RL: Osteosarcoma of the jaw: an analysis of 74 cases. Histopathology 2013 (E-publication 5-17-13) (Accessed 10-11-13).

29. Campanacci M. Osteofibrous dysplasia of the long bones—a new clinical entity. Ital J Orthop Traumatol 1976;2:221237.

30. Campanacci M, Laus M. Osteofibrous dysplasia of the tibia and fibula. J Bone Joint Surg (Am) 1981;63:367-375.

31. Castellote A, Garcia-Pena P, Lucaya J, Lorenzo J. Osteofibrous dysplasia. A report of two cases. Skeletal Radiol 1988; 17:483-486.

32. Park Y-K., Unni KK, McLeod RA, Pritchard DJ. Osteofibrous dysplasia: clinicopathologic study of 80 cases. Hum Pathol 1993;24:1339-1347.

33. Markel SF. Ossifying fibroma of long bone. Its distinction from fibrous dysplasia and its association with adamantinoma of long bone. Am J Clin Pathol 1978;69:91-97. 
34. Benassi MS, Campanacci L, Gamberi G, et al. Cytokeratin expression and distribution in adamantinoma of the long bones and osteofibrous dysplasia of tibia and fibula. An immunohistochemical study correlated to histogenesis.

Histopathology 1994;25:71-76.

35. Ishida T, Iijima T, Kikuchi F, et al. A clinicopathological and immunohistochemical study of osteofibrous dysplasia, differentiated adamantinoma and adamantinoma of long bones. Skeletal Radiol 1992;21:493-512.

36. Sweet DE, Vihn TN, Devaney K. Cortical osteofibrous dysplasia of long bone and its relationship to adamantinoma. Am J Surg Pathol 1992;16:282-290.

37. Baker PL, Dockerty MB, Coventry MB. Adamantinoma (so-called) of the long bones. Review of the literature and a report of three new cases. J Bone Joint Surg (Am) 1954;36:704-720.

38. Campanacci M, Laus M, Guinti A, Gitalis S, Bertoni F. Adamantinoma of the long bones. The experience of the Instituto Ortopedico Rizzolo. Am J Surg Pathol 1981;5:533-542.

39. Czerniak B, Rojas-Corona RR, Dorfman HD. Morphologic diversity of long bone adamantinoma. The concept of differentiated (regressing) adamantinoma and its relationship to osteofibrous dysplasia. Cancer 1989;64:2319-2334

40. Keeney GL, Unni KK, Beabout JW, Pritchard DJ. Adamantinoma of long bones. A clinicopathologic study of 85 cases. Cancer 1989;64:730-737.

41. Pieterse AS, Smith PS, McClure J. Adamantinoma of long bones: clinical, pathological, and ultrastructural features. $J$ Clin Pathol 1982;35:780-786.

42. Weiss SW, Dorfman HD. Adamantinoma of long bone. An analysis of nine new cases with emphasis on metastasizing lesions and fibrous dysplasia-like changes. Hum Pathol 1977;8:141-153.

43. Rosai J, Pinkus GS. Immunohistochemical demonstration of epithelial differentiation in adamantinoma of the tibia. Am J Surg Pathol 1982;6:427-434.

44. Johnson LC. Congenital pseudoarthrosis, adamantinoma of long bone and intracortical fibrous dysplasia of the tibia. $J$ Bone Joint Surg (Am) 1972;54:1355-1358.

45. Ueda Y, Roessner A, Bosse A, Edel G, Bocker W. Juvenile intracortical adamantinoma of the tibia with predominantly osteofibrous dysplasia-like features. Pathol Res Pract 1991;187:1039-1043.

46. Bridge JA, Dembinski A, De Boer J, Travis J, Neff JR. Clonal chromosomal abnormalities in osteofibrous dysplasia. Implications for histopathogenesis and its relationship with adamantinoma. Cancer 1994;73:1746-1752.

47. Kashima TG, Dongre A, Flanagan AM, Hogendoorn PC, Taylor R, Athanasou NA: Podoplanin expression in adamantinoma of long bones and osteofibrous dysplasia. Virchows Arch 2011; 459: 41-46.

48. Caffey J. On fibrous defects in cortical walls of growing tubular bones: their radiologic appearance, structure, prevalence, natural course, and diagnostic significance. Adv Pediatr 1955;7:13-51.

49. Cunningham JB, Ackerman LV. Metaphyseal fibrous defects. J Bone Joint Surg (Am) 1956;38:797-808.

50. Hatcher CH. The pathogenesis of localized fibrous lesions in the metaphysis of long bones. Ann Surg 1945;122:10161030.

51. Ritschl P, Karmel F, Hajek P. Fibrous metaphyseal defects—-determination of their origin and natural history using a radiomorphological study. Skeletal Radiol 1988;17:8-15.

52. Moser RP Jr, Sweet DR, Hanseman DB, Madewell JE. Multiple skeletal fibroxanthomas: radiologic-pathologic correlation of 72 cases. Skeletal Radiol 1987;16:353-359.

53. Mirra JM, Gold RH, Rand F. Disseminated nonossifying fibromas in association with cafe-au-lait spots (JaffeCampanacci syndrome). Clin Orthop 1982;168:192-205.

54. Arata MA, Peterson HA, Dahlin DC. Pathologic fracture through nonossifying fibroma. Review of the Mayo Clinic experience. J Bone Joint Surg (Am) 1981;63:980-988.

55. Bejarano PA, Kyriakos M. Nonossifying fibroma of long bones. An immunohistochemical study. Appl Immunohistochem 1995;3:257-264.

56. Kyriakos M, Murphy WA. Concurrence of metaphyseal fibrous defect and osteosarcoma. Report of a case and review of the literature. Skeletal Radiol 1981;6:179-186.

57. Bertoni F, Calderoni P, Bacchini P, et at. Benign fibrous histiocytoma of bone. J Bone Joint Surg (Am) 1986;68:12251230.

58. Clarke BE, Xipell JM, Thomas DP. Benign fibrous histiocytoma of bone. Am J Surg Pathol 1985;9:806-815.

59. Roessner A, Immenkamp M, Weidner A, Hobik HP, Grundmann E. Benign fibrous histiocytoma of bone. Light-and electron-microscopic observations. J Cancer Res Clin Oncol 1981;101:191-202.

60. Auclair PL, Cuenin P, Kratochvil FJ, Slater LJ, Ellis GL. A clinical and histomorphological comparison of the central giant cell granuloma and the giant cell tumor. Oral Surg Oral Med Oral Pathol 1988;66:197-208.

61. Jaffe HL. Giant-cell reparative granuloma, traumatic bone cyst, and fibrous (fibro-osseous) dysplasia of the jawbones. Oral Surg Oral Med Oral Pathol 1953;6:159-175.

62. Waldron CA, Shafer WG. The central giant cell reparative granuloma of the jaws. An analysis of 38 cases. Am J Clin Pathol 1966;45:437-447.

63. Hirschl S, Katz A. Giant cell reparative granuloma outside the jaw bone. Diagnostic criteria and review of the literature with the first case described in the temporal bone. Hum Pathol 1974;5:171-181.

64. Yamaguchi T, Dorfman HD: Giant cell reparative granuloma: a comparative clinicopathologic study of lesions in gnathic and extragnathic sites. Int J Surg Pathol 2001; 9: 189-200. 
65. Hamner JE III, Ketcham AS. Cherubism: an analysis of treatment. Cancer 1969;23:1133-1143.

66. Gamage NM, Kashima TG, McNally MA, et al.: Giant cell-rich pseudotumor in Paget's disease. Skeletal Radiol 2013; 42: 595-599.

67. Haibach H, Farrell C, Dittrich FJ: Neoplasms arising in Paget's disease of bone: a study of 82 cases. Am J Clin Pathol 1985; 83: 594-600.

68. Hoch B, Hermann G, Klein MJ, Abdelwahab IF, Springfield D: Giant cell tumor complicating Paget disease of long bone. Skeletal Radiol 2007; 36: 973-978.

69. Caskey PM, Wolf MD, Fechner RE. Multicentric giant cell reparative granuloma of the small bones of the hand. A case report and review of the literature. Clin Orthop 1985;193:199-205.

70. Glass TA, Mills SE, Fechner RE, et al. Giant cell granulomas of the hands and feet. Radiology 1983;149:65-68.

71. Lorenzo JC, Dorfman HD. Giant cell reparative granuloma of the short tubular bones of the hands and feet. Am J Surg Pathol 1980;4:551-563.

72. Picci P, Baldini N, Sudanese A, Boriani S, Campanacci M. Giant cell reparative granuloma of the bones of the hands and feet. Skeletal Radiol 1986;15:415-421.

73. Ratner V, Dorfman HD. Giant cell reparative granuloma of the hand and foot hones. Clin Orthop 1990;260:251-258.

74. Wold LC, Dobins JH, Swee RG, Dahlin DC. Giant cell reaction (giant cell reparative granuloma) of the small bones of the hand and feet Am J Surg Pathol 1986;10:491-496.

75. Doussis I A, Puddle B, Athanasou NA. Immunophenotype of multinucleated and mononuclear cells in giant cell lesions of bone and soft tissue. J Clin Pathol 1992;45:398-404.

76. Unni KK, McLeod RA, Dahlin DC: Conditions that simulate primary neoplasms of bone. Pathol Annu 1980; 15(Part 1): $91-131$.

77. Meydan N, Barutca S, Guney E, et al.: Brown tumors mimicking bone metastases. J Natl Med Assoc 2006; 98: 950953.

78. Bassler T, Wong ET, Brynes RK: Osteitis fibrosa cystica simulating metastatic tumor: an almost-forgotten relationship. Am J Clin Pathol 1993; 100: 697-700.

79. Bertoni F, Bacchini P, Capanna R, et al. Solid variant of aneurysmal bone cyst. Cancer 1993;71:729-734.

80. Ruiter DJ, Van Rijssel TG, van der Velde EA. Aneurysmal bone cyst. A clinicopathologic study of 105 cases. Cancer 1977;39:2231-2239.

81. Vergel De Dios AM, Bond JR, Shives TC. McCleod RA, Unni KK. Aneurysmal none cyst. A clinicopathologic study of 238 cases. Cancer 1992;69:2921-2931.

82. Baumsgaard P, Nielsen BB. Primary synovial chondrometaplasia. Histologic variations in the structure of metaplastic nodules. Acta Pathol Microbiol Immunol Scand (A) 1984;92:455-460.

83. Jeffreys TE. Synovial chondromatosis. J Bone Joint Surg (Br) 1967;49:530-534.

84. Milgram JW. Synovial osteochondromatosis. A histopathological study of thirty cases. J Bone Joint Surg (Am) 1977;59:792-801.

85. Murphy FP, Dahlin DC, Sullivan CR. Articular synovial chondromatosis. J Bone Joint Surg (Am) 1962;44:77-86.

86. Villacin AB, Brigham LN, Bullough PG. Primary and secondary synovial chondrometaplasia. Histopathological and clinicoradiologic differences. Hum Pathol 1979;10:439-451.

87. Skalski M, Datir A: Primary synovial chondromatosis (E-publication). http://radiopaedia.org/articles/primary-synovialchondromatosis. (Accessed 10-7-213).

88. Davis RI, Hamilton A, Biggart JD: Primary synovial chondromatosis: a clinicopathologic review and assessment of malignant potential. Hum Pathol 1998; 29: 683-688.

89. Sim FH, Dahlin DC, Ivins JC. Extra-articular synovial chondromatosis. J Bone Joint Surg (Am) 1977;59:492-495.

90. Dunn AW, Whisler JH: Synovial chondromatosis of the knee with associated extracapsular chondromas. J Bone Joint Surg (Am) 1973; 55: 1747-1748.

91. Sviland L, Malcolm AJ. Synovial chondromatosis presenting as painless soft tissue mass-a report of 19 cases. Histopathology 1995;27:275-279.

92. Sariento A, Elkins RW. Giant intra-articular osteochondroma of the knee. J Bone Joint Surg (Am) 1975;57:560-561.

93. Bertoni F, Unni KK, Beabout JW, Sim FH. Chondrosarcomas of the synovium. Cancer 1991;67:155-162.

94. Kenan S, Abdelwahab IF, Klein MJ, et al.: Synovial chondrosarcoma secondary to synovial chondromatosis. Skeletal Radiol 1993; 22: 623-626.

95. Hamilton A, Davis RI, Hayes D, Mollan RA. Chondrosarcoma developing in synovial chondromatosis. A case report. $J$ Bone Joint Surg (Br) 1987;69:137-140.

96. Perry BE. McQueen DA, Lin JJ. Synovial chondromatosis with malignant degeneration lo chondrosarcoma. Report of a case. J Bone Joint Surg ( Am) 1988;70:1259-1261.

97. Biesecker JL, Marcove RC, Huvos AG, Mike V. Aneurysmal bone cysts. A clinicopathologic study of 66 cases. Cancer 1970;26:615-625.

98. Campana R, Betelli G, Biagin R, Ruggieri P, Bertoni F, Campanacci M. Aneurysmal cysts of long bones. Ital J Orthop Traumatol 1985;11:409-417.

99. Dahlin DC, MeLeod RA. Aneurysmal bone cyst and other non-neoplastic conditions. Skeletal Radiol 1982;8:243-250. 
100. Tillman BP, Dahlin DC, Lipscomb PR, Stewart JR. Aneurysmal bone cyst: analysis of ninety-five cases. Mayo Clin Proc 1968;43:478-495.

101. Frassica FJ, Amadio PC, Wold LE, Beabout JW. Aneurysmal bone cyst: clinicopathologic features and treatment of ten cases involving the hand. J Hand Surg 1988;13A:676-683.

102. Sherman RS, Soong KY. Aneurysmal bone cyst: its roentgen diagnosis. Radiology 1957;68:54-64.

103. Burnstein MI, De Smet AA, Gholam RH, Heiner JP. Case report 611 (subperiosteal aneurysmal bone cyst of tibia). Skeletal Radiol 1990;19:294-297.

104. Bonakdarpour A, Levy WM, Aegeter E. Primary and secondary aneurysmal bone cyst: a radiological study of 75 cases. Radiology 1978;126:75-83.

105. Dehner LP, Risdall RJ, Heureux P. Giant cell containing fibrous lesion of the sacrum. A roentgenographic, pathologic, and ultrastructural study of three cases. Am J Surg Pathol 1978;2:55-70.

106. Oda Y, Tsuneyoshi M, Shinohara N. Solid variant of aneurysmal bone cyst (extragnathic giant cell reparative granuloma) in the axial skeleton and long bones. A study of its morphologic spectrum and distinction from allied giant cell lesions. Cancer 1992;70:2642-2649.

107. Aho HJ, Aho AJ, Pelliniemi LJ, Ekfors TO, Poidart JM. Endothelium in aneurysmal bone cyst. Histopathology 1985:9:381-387.

108. Alles JU, Schulz A. Immunohistochemical markers (endothelial and histiocytic) and ultrastructure of primary aneurysmal bone cyst. Hum Pathol 1986;17:39-15.

109. Clough JR. Price CH. Aneurysmal bone cyst: pathogenesis and long term results of treatment. Clin Orthop 1973;97:52-63.

110. Sanerkin NG, Molt MG, Roylance J. An unusual intraosseous lesion with fibroblastic, osteoclastic, osteoblastic, aneurysmal and fibromyoid elements. Solid variant of aneurysmal bone cyst. Cancer 1983;51: 2278-2286.

111. Buraczewski J, Dabska M. Pathogenesis of aneurysmal bone cyst. Relationship between the aneurysmal bone cyst and fibrous dysplasia of bone. Cancer 1971;28:597-604.

112. Levy WM, Miller AR, Bonakdarpour A, Aegeter E. Aneurysmal bone cyst secondary to other osseous lesions: report of 57 cases. Am J Clin Pathol 1975;63:18-32.

113. Liu JJ, Liu S, Wang JG, et al.: Telangiectatic osteosarcoma: a review of literature. Oncol Targets Ther 2013; 6: 593602.

114. Colomina J, Peiro A, Trullols L, Garcia I: Telangiectatic osteosarcoma. J Orthop Surg 2013; 21: 96-99.

115. Sangle NA, Layfield LJ: Telangiectatic osteosarcoma. Arch Pathol Lab Med 2012; 136: 572-576.

116. Lee HM, Cho KS, Choi KU, Roh HJ: Aggressive aneurysmal bone cyst of the maxilla confused witih telangiectatic osteosarcoma. Auris Nasis Larynx 2012; 39: 337-340.

117. Durnali A, Alkis N, Canqur S, et al.: Prognostic factors for teenage and adult patients with high-grade osteosarcoma: an analysis of 240 patients. Med Oncol 2013; 30: 624 (E-publication 6-9-13) (Accessed 10-11-13).

118. Kyriakos M, Hardy D. Malignant transformation of aneurysmal bone cyst, with analysis of the literature. Cancer 1991;68:1770-1780.

119. Mercuri LG: Acute osteomyelitis of the jaws. Oral Maxillofac Surg Clin North Am 1991; 3: 355-365.

120. McCarville MB: The child with bone pain: malignancies and mimickers. Cancer Imaging 2009; 9: S115-S121.

121. Gulmann C, Young O, Tolan M, O'Riordan D, Leader M: Chronic osteomyelitis mimicking sarcoma. J Clin Pathol 2003; 56: 237-239.

122. Cabanela ME, Sim FH, Beabout JW, Dahlin DC: Osteomyelitis appearing as neoplasms: a diagnostic problem. Arch Surg 1974; 109: 68-72.

123. Henninger B, Glodny B, Rudisch A, et al.: Ewing sarcoma versus osteomyelitis: differential diagnosis with magnetic resonance imaging. Skeletal Radiol 2013; 42: 1097-1104.

124. Sheppard JE, Switlick DN: Coccidioides immitis osteomyelitis of the radius presenting as Ewing's sarcoma. Orthopedics 2008; 31: 607.

125. Tow BP, Tan MH: Delayed diagnosis of Ewing's sarcoma of the right humerus initially treated as chronic osteomyelitis: a case report. J Orthop Surg 2005; 13: 88-92.

126. Museru LM, McHaro CN: Chronic osteomyelitis: a continuing orthopedic challenge in developing countries. Int Orthop 2001; 25: 127-131.

127. Durbin M, Randall RL, James M, Sudilovsky D, Zoger S: Ewing's sarcoma masquerading as osteomyelitis. Clin Orthop Relat Res 1998; 357: 176-185.

128. Abril JC, Castillo F, Casas J, Diaz A: Brodie's abscess of the hip simulating osteoid osteoma. Orthopedics 2000; 23: 285-287.

129. Bhagavathi S, Fu K: Primary bone lymphoma. Arch Pathol Lab Med 2009; 133: 1868-1871.

130. Desai S, Jambhekar NA, Soman CS, Advani SH: Primary lymphoma of bone: a clinicopathologic study of 25 cases reported over 10 years. J Surg Oncol 1991; 46: 265-269.

131. Beal K, Allen L, Yahalom J: Primary bone lymphoma: treatment results and prognostic factors with long-term followup of 82 patients. Cancer 2006; 106: 2652-2656. 
132. Ramadan KM, Shenkler T, Sehn LH, Gascoyne RD, Connores JM: A clinicopathologic retrospective study of 131 patients with primary bone lymphoma: a population-based study of successively-treated cohorts from the British Columbia Cancer Agency. Ann Oncol 2007; 18: 129-135.

133. Ostrowski ML, Unni KK, Banks PM, et al.: Malignant lymphoma of bone. Cancer 1986; 58: 2646-2655.

134. Baltensperger M, Gratz K, Bruder E, Lebeda R, Makek M, Eyrich G: Is primary chronic osteomyelitis a uniform disease? Proposal of a classification based on a retrospective analysis of patients treated in the past 30 years. $J$ Craniomaxillofac Surgf 2004; 32: 43-50.

135. Suei Y, Tanimoto K, Taguchi A, Wada T, Ishikawa T: Chronic recurrent multifocal osteomyelitis involving the mandible. Oral Surg Oral Med Oral Pathol 1994; 78: 156-162.

136. Chow LT, Griffith JF, Kumta SM, et al.: Chronic recurrent multifocal osteomyelitis: a great clinical and radiologic mimic in need of recognition by the pathologist. APMIS 1999; 107: 369-379.

137. Fitzgerald RH Jr, Brewer NS, Dahlin DC: Squamous-cell carcinoma complicating chronic osteomyelitis. J Bone Joint Surg (Am) 1976; 58: 1146-1148.

138. Roodman GD, Windle JJ: Paget disease of bone. J Clin Invest 2005; 115: 200-208.

139. Whitehouse RW: Paget's disease of bone. Semin Musculoskelet Radiol 2002; 6: 313-322.

140. Wick MR, Siegal GP, Unni KK, McLeod RA, Greditzer HG III: Sarcomas of bone complicating osteitis deformans (Paget's disease): fifty years' experience. Am J Surg Pathol 1981; 5: 47-59.

141. Deyrup AT, Montag AG, Inwards CY, Xu Z, Swee RG, Unni KK: Sarcomas arising in Paget disease of bone: a clinicopathologic analysis of 70 cases. Arch Pathol Lab Med 2007; 131: 942-946.

142. Huvos AG, Butler A, Bretsky SS: Osteogenic sarcoma associated with Paget's disease of bone: a clinicopathologic study of 65 patients. Cancer 1983; 52: 1489-1495.

143. McNairn JDK, Damron TA, Landas SK, Ambrose JL: Benign tumefactive soft tissue extension from Paget's disease of bone simulating malignancy. Skeletal Radiol 2001; 30: 157-160.

144. Bowerman JW, Altman J, Hughes JL, Zadek RE: Pseudomalignant lesions in Paget's disease of bone. Am J Roentgen Radiother Nucl Med 1975; 124: 57-61.

145. Khraishi M, Howard B, Fam AG: Paget's pseudosarcoma. Arthritis Rheum 1991; 34: 241-243.

146. Lamovec J, Rener M, Spiler M: Pseudosarcoma in Paget's disease of bone. Ann Diagn Pathol 1999; 3: 99-103.

147. Franchi A, Bacchini P, Della Rocca C, Bertoni F: Central low-grade osteosarcoma with pagetoid bone formation: a potential diagnostic pitfall. Mod Pathol 2004; 17: 288-291.

148. Huang WC, Chang $\mathrm{CH}$, Tsai CC: Polyvinylpyrrolidone storage disease presenting as pathologic fracture and anemia: report of a case with imprint cytology. Diagn Cytopathol 2012; 40: 69-72.

149. Reske-Nielsen E, Boisen-Moller M, Vetner M, Hansen JC: Polyvinylpyrrolidone-storage disease: light microscopical, ultrastructural, and chemical verification. Acta Pathol Microbiol Scand A 1976; 84: 397-405.

150. Dunn P, Kuo TT, Shih LY, Wang PN, Sun CF, Chang MJ: Bone marrow failure and myelofibrosis in a case of PVP storage disease. Am J Hematol 1998; 57: 68-71.

151. Hewan-Lowe K, Hammers Y, Lyons JM, Wilcox CM: Polyvinylpyrrolidone storage disease: a source of error in the diagnosis of signet ring cell gastric adenocarcinoma. Ultrastruct Pathol 1994; 18: 271-278.

152. Kuo TT, Hsueh S: Mucicarminophilic histiocytosis: a polyvinylpyrrolidone (PVP) storage disease simulating signetring-cell carcinoma. Am J Surg Pathol 1984; 8: 419-428.

153. Kuo TT, Hu S, Huang CL, et al.: Cutaneous involvement in polyvinylpyrrolidone storage disease: a clinicopathologic study of five patients, including two patients with severe anemia. Am J Surg Pathol 1997; 21: 1361-1367.

154. Bubis JJ, Cohen S, Dinbar J, Hirschhorn B, Szeinberg A, Wolman M: Polyvinylpyrrolidone mimicking a congenital mucolipid storage disease in a patient with Munchausen's syndrome. Isr J Med Sci 1975; 11: 999-1004.

155. Raith K, Kuhn AV, Rosche F, Wolf R, Neubert RHH: Characterization of povidone products by means of 13-C-NMR, MALDI-TOF, and electrospray mass spectrometry. Pharm Res 2002; 19: 556-561. 


\section{FIGURE LEGENDS}

1. Fibrous dysplasia of bone can be monostotic (left image) or polyostotic (middle image). It is characterized by a bland fibroblastic proliferation which entraps osteoid profiles with "mechanically-nonsensical" images. There is no osteoblastic proliferation or nuclear atypicality.

2. Low-grade central osteosarcoma (LGCO) is seen here as an ill-defined sclerotic mass in the femoral diaphysis (left). Histologically, it shows interlocking trabeculae of osteoid (top, right) that are mantled by atypical osteoblasts (bottom, left). An immunostain for mouse double-minute-2 (MDM2) homolog protein shows multifocal nuclear reactivity in LGCO.

3. Desmoplastic fibroma of the ulna is a diaphyseal lesion that has essentially destroyed the integrity of that bone (left). It comprises generally-parallel arrays of cytologically-bland fibroblasts, admixed with dense, mature collagen (right top \& bottom). This tumor has no real histological resemblance to fibrous dysplasia.

4. Additional microscopic differential diagnostic alternatives to fibrous dysplasia include (clockwise from top left) welldifferentiated fibrosarcoma; solid aneurysmal bone cyst; osteoid osteoma; and osteoblastoma.

5. Ossifying fibroma of the left maxilla is shown in a computed tomogram (top left) and a clinical photograph (top right). Histologically, this lesion forms variably-sized and -shaped osteoid trabeculae in a fibroblastic stroma, as seen in fibrous dysplasia. Indeed, it may be virtually impossible in some cases to separate those two entities diagnostically.

6. Cemento-ossifying fibroma of the jaws (left- shown in a plain-film image in the left mandible) synthesizes matrix material that resembles cementum (right panels), and it may assume a "psauuomatoid" concentric configuration.

7. Osteosarcomas of the jaws differ from ossifying fibroma and cemento-ossifying fibroma by being infiltrative (left panel) and showing the production of "lacy" osteoid matrix (right). The lesional cells also manifest overt nuclear atypia.

8. Fibro-osseous dysplasia of bone is architecturally similar to fibrous dysplasia (FD) at a general level. However, it is virtually always seen in the bones of the lower legs in young male patients (left panel), and its constituent osteoid trabeculae are mantled by osteoblasts. Differential diagnostic considerations are similar to those attending FD (see figures $3 \& 4$ ).

9. The most singular aspect of fibro-osseous dysplasia is its possible evolution to adamantinoma of bone, as shown here radiographically and grossly (left \& middle images). Adamantinoma is an epithelial neoplasm comprising nests of compact polygonal cells (right panels) which are immunoreactive for pankeratin.

10. Metaphyseal fibrous defect (MFD; also known as non-ossifying fibroma) of bone is again characteristically seen in the bones of the lower legs in young male patients. MFD shows sharp radiographic margination (left panel), and is constituted by cytologically-bland spindle cells, foamy histiocytes, and osteoclast-like giant cells (right panels). As such, it is virtually impossible to distinguish morphologically from osseous "fibrous histiocytoma" or "fibroxanthoma" in other anatomic locations.

11. Giant cell reparative granuloma (GCRG) is most often encountered in the jawbones, as shown in this computed tomogram in the left maxilla (left panel). Microscopically, it shows a proliferation of fusiform and ovoid stromal cells with no nuclear atypicality, punctuated by an irregular distribution of osteoclast-like giant cells (right panels).

12. GCRG may also occur in the small bones of the hands and feet, where its histological appearance is comparable to that of gnathic lesions.

13. In contrast to GCRG, true giant cell tumors are principally found in the epiphyses of long bones in adults (left panel). They are fleshy, tan-brown masses macroscopically (middle), which demonstrate an even distribution of osteoclast-like giant cells amongst cytologically-bland mononuclear stromal cells (right panels).

14. "Brown tumors" of hyperparathyroidism are preferentially found in the vertebrae, distal clavicles, jawbones, and symphysis pubis, the last of which pertains to the left panel. Microscopically, this lesion exhibits a proliferation of fibroblasts admixed with osteoclast-like giant cells and ovoid stromal cells (top, right). Adjacent bones often show osteoclastic activity (bottom, right).

15. Synovial chondromatosis-chondrometaplasia is typically a monoarticular, multinodular soft tissue lesion that often shows secondary calcification (left panel). It comprises variably-sized nests of chondrocytes that can exhibit moderate hypercellularity and even binucleation (right panels), as potentially seen in low-grade chondrosarcomas of bone.

16. True chondrosarcomas are characteristically metaphyseal or diaphyseal intraosseous lesions that often display internal calcifications (left panel). They are relatively well-circumscribed and translucent grossly (middle panel). These tumors manifest obvious nuclear atypia microscopically, with or without binucleation or multinucleation of the neoplastic cells (right panel).

17. Aneurysmal bone cysts (ABCs) preferentially occur in children, adolescents, and young adults, and can be metaphyseal or diaphyseal. They have variably-distinct borders in plain film radiographs or by gross inspection (left \& middle panels), and exhibit the formation of blood-filled spaces that are mantled by tissue comprising cytologically-banal ovoid stromal cells and osteoclast-like elements (right panels). The giant cells in ABC tend to be concentrated immediately beneath the blood-filled spaces.

18. The main differential diagnostic alternative to $\mathrm{ABC}$ is that of telangiectatic osteosarcoma (TOS). That neoplasm is a destructive and highly-vascular lesion (top panels). It comprises solid, osteoid-producing cellular expanses and bloodfilled spaces surrounded by attenuated cords of tumor cells that display overt nuclear atypicality (bottom panels). 
19. Chronic osteomyelitis (CO) of the calcaneus is shown here, forming a "Brodie abscess" that radiographically simulates the image of osteoid osteoma (left panel). CO shows chronically-inflamed fibrous tissue that replaces the normal bony medulla and is punctuated by bars of proliferating cortical bone (right panel).

20. This example of osteoid osteoma in the right third finger has a radiographic appearance which is similar to that shown in the previous figure (left \& middle panels). However, unlike CO, osteoid osteoma contains a central "nidus" that is composed of interanastomosing osteoid trabeculae which are mantled by osteoblasts (right panels).

21. Selected examples of osteomyelitis may produce a radiographic picture which simulates that of Ewing sarcoma (ES), with proliferation of the overlying periosteum (left \& middle panels). Unlike CO, ES is constituted by sheets of compact ovoid tumor cells with high nucleocytoplasmic ratios (top, right), and cytoplasmic glycogen content (bottom, right- periodic acid-Schiff stain).

22. Chronic osteomyelitis also may resemble the image of osseous non-Hodgkin lymphoma (left panel) in some instances. Again, however, lymphoma is represented by a monomorphous population of tumor cells (top, right) which usually express CD20 immunohistochemically (bottom, right).

23. In approximately $1 \%$ of cases of Paget disease of bone (PDB), a secondary sarcoma develops that is typically an obviously-destructive lesion (left panel). Osteosarcomas (top, right), fibrosarcomas (bottom, right), or other osseous malignancies may represent the sarcomas of PDB.

24. In a very small proportion of osseous Paget disease cases, the primry disorder itself can assume a proliferative form in which numerous deformed and large osteoid trabeculae are formed. That eventuality can present a radiographic image which mimics that of Paget sarcoma (left panel). Nevertheless, biopsies of such lesions show only the histological appearances of PDB (right panels).

25. Polyvinylpyrrolidone (PVP) is a polymeric substance that has been used as a constituent of various pharmaceutical agents including plasma expanders. It is not excretable by the body and can accumulate in various bony sites, where it can simulate a neoplasm radiographically (top, left-magnetic resonance image of L3 vertebra). Histologically, PVP storage disease shows sheets of large vacuolated epithelioid cells, which represent macrophages (top right, bottom left). However, they can be confused with such true neoplasms as chordoma, benign notochordal tumors, or metastatic mucinous adenocarcinoma, and the mucicarminophilia of PVP (bottom, right) heightens this histologic resemblance. 